\title{
10.21611/qirt.2016.009
}

\section{IR thermography applied to flash experiments of semitransparent TBCs.}

\author{
by P. Bison ${ }^{1}$, S. Boldrini ${ }^{2}$, F. Cernuschi ${ }^{3}$
}

CNR-ITC, C.so Stati Uniti 4, 35127 Padova, Italy CNR-IENI, C.so Stati Uniti 4, 35127 Padova, Italy RSE, via Rubattino 54, 20134 Milano, Italy

\section{Abstract}

Thermal Barrier Coatings (TBC) are applied to protect components of gas turbines from high temperature of combustion gases. $\mathrm{ZrO}_{2}$, the material mainly used in TBCs, is semitransparent to near IR radiation that is typically delivered by the laser in the laser flash equipment and also radiated at working temperatures that are grater than $1000{ }^{\circ} \mathrm{C}$. Thermography and radiometers are utilized to measure thermal diffusivity of TBCs. Discussion is done on the countermeasures to obtain correct results in case of semitransparency.

\section{Introduction}

Thermal Barrier Coatings (TBCs) are applied to protect components of gas turbines from high temperature combustion gases (see in Fig. 1 a gas turbine system for electrical power production under maintenance). Typically, they are metalceramic multi-layers structures made up of a yttria partially stabilized zirconia (7-8 wt. $\% \mathrm{Y}_{2} \mathrm{O}_{3}+\mathrm{ZrO}_{2}$ ) deposited either by Air Plasma Spray (APS) or Electron Beam-Physical Vapour Deposition (EB-PVD) on a high temperature oxidation/corrosion resistant metallic Bond Coat (BC) (see Fig. 2).

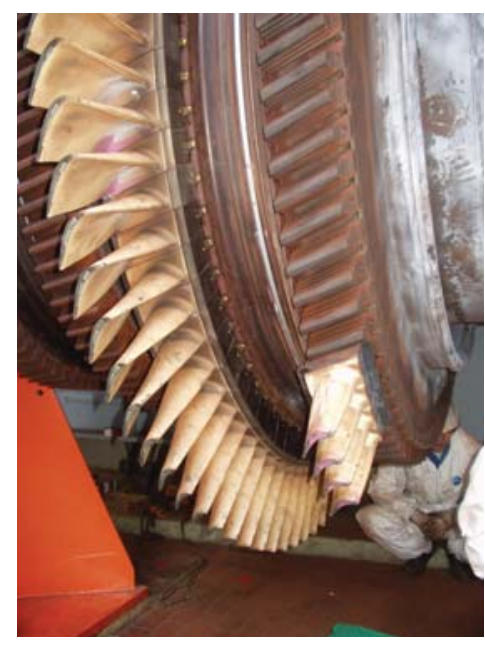

Fig. 1. A gas turbine system for electrical power production, under maintenance.

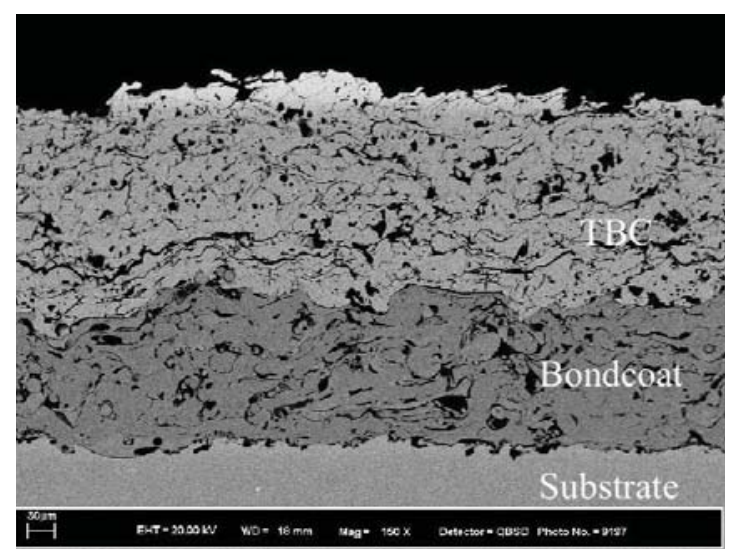

Fig. 2. A typical metal-ceramic multi-layers structures of a gas turbine combustion chamber: yttria partially stabilized zirconia (7-8 wt.\% $\mathrm{Y}_{2} \mathrm{O}_{3}+\mathrm{ZrO}_{2}$ ) deposited either by APS or $E B-P V D$ on a high temperature oxidation/corrosion resistant metallic bond coat $(B C)$ to protect the metallic substrate.

The refractory ceramic porous layer can reduce the temperature of the metallic substrate by $30^{\circ} \mathrm{C}$ to $100^{\circ} \mathrm{C}$, depending on the thickness and on the specific microstructural properties of the coating. Under typical working conditions, gas turbines are subjected to several switching on and off with consequent cyclic variations of temperature of TBCs, from ambient to working temperature $\left(>1000{ }^{\circ} \mathrm{C}\right)$. That leads both to mechanical stress and to sintering phenomena that changes the characteristics of TBCs reducing the mechanical compliance and the insulating properties (see Fig. 3). 


\section{(Air Plasma Spray deposition)}
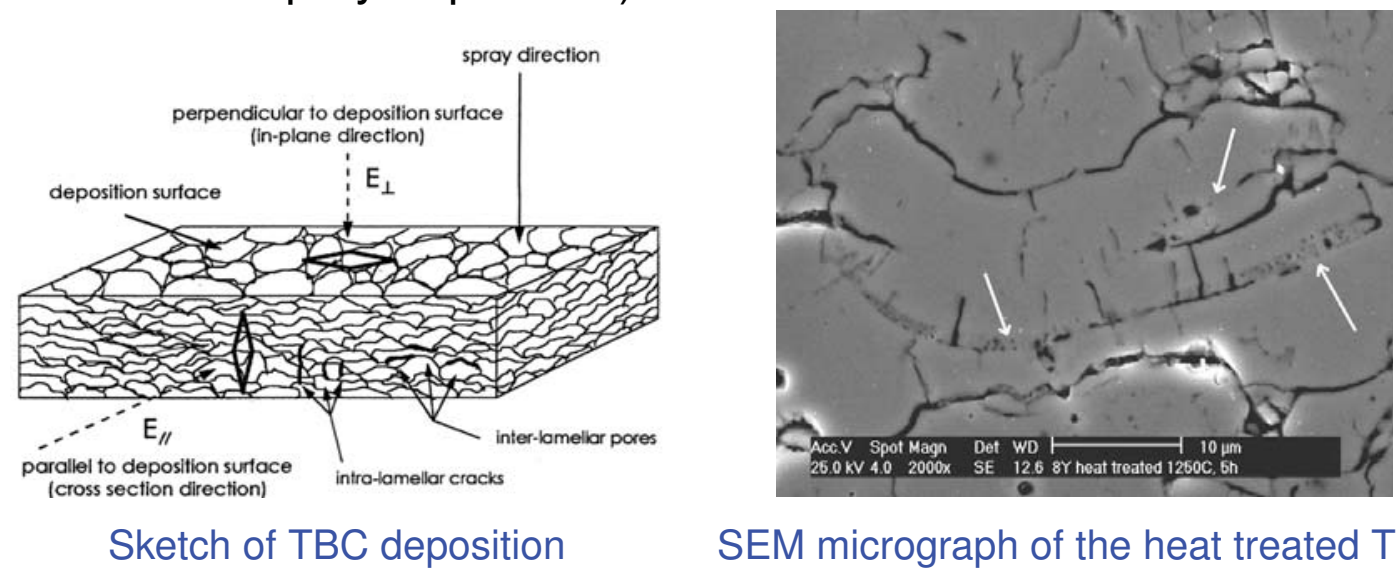

SEM micrograph of the heat treated TBC

Fig. 3. Scheme of TBC deposition by Air Plasma Spray technology and SEM micrograph showing the sealing of microcracks (see the arrows) due to sintering phenomena promoted by high temperature exposition. Reduction of microcracks reduces the strain compliance of the TBC under temperature variation and thermal expansion.

Measuring the variation of thermal parameters on TBCs subjected to artificial cyclic temperature variation is a way to assess the ageing effects [1]. Typically, thermal diffusivity of TBCs is determined by a laser flash apparatus [2] and IR thermography as well, both in transmission and reflection scheme [3-5]. Unfortunately, $\mathrm{ZrO}_{2}$ is semitransparent to near IR radiation that is typically delivered by the laser in the laser flash equipment. Moreover, the characterization of TBCs at high temperatures is particularly interesting as the typical working temperature of gas-turbine is $>1000{ }^{\circ} \mathrm{C}$. At these temperatures heat transfer is no more limited to conduction and the radiative heat transfer becomes paramount [6,7]:

- $\mathrm{Y}_{2} \mathrm{O}_{3}+\mathrm{ZrO}_{2}$ is fairly transparent to radiation with wavelength $\lambda<5 \mu \mathrm{m}$

- i.e. typical laser shot $(\lambda=1064 \mathrm{~nm})$ pass through

- heat is transmitted by radiation for T > RoomTemp

- it is semitransparent for $5 \mu \mathrm{m}<\lambda<8 \mu \mathrm{m}$

- it is almost opaque for $\lambda>8 \mu \mathrm{m}$

- heat is not transmitted by radiation around RoomTemp

- being a white oxide its reflectance is quite high for $1<\lambda<5 \mu \mathrm{m}$

The evaluation of effective heat conduction is carried out in this work by laser flash equipment and IR thermography as well. The effects of blackening the surfaces by a thin layer of graphite is considered [8]. The role of heat conduction and radiation is also taken into account trying to separate each contribution. Experiments are carried out at ambient temperature by means of a thermographic camera and, at higher temperature, in vacuum until $1200{ }^{\circ} \mathrm{C}$ by means of a laser flash equipment and in argon atmosphere by means of another laser flash system (from another manufacturers) until $900^{\circ} \mathrm{C}$. Data are treated according to classical scheme taking into account the exchange with the environment [9]. Successively the data are considered by using the possibility of radiative exchange between the two blackened sides of the sample [10]. The possibility of simultaneous heating of the two sides of the sample, due to the semitransparency of the material to the laser shot is introduced, giving rise to a new model that explains in some conditions anomalous immediate heating of the side facing the detector. Results are shown and explained by using all the mathematical models presented. 


\subsection{1/qirt.2016.009}

\section{Modeling}

Nowadays the Laser Flash method [2, 11, 12] is the most frequently used photothermal technique to measure thermal diffusivity. This method consists of heating the front face of a sample (typically a small disk-shaped specimen) by a short laser pulse and detecting the temperature evolution on its rear surface. The scheme is described in Fig. 4. The main advantages of this method are its simplicity and rapidity of measurement, and the possibility to measure the thermal diffusivity on a wide range of materials at different temperatures. The mathematical model utilized to describe the heat conduction problem that arises in the Laser Flash experiment is the following :

- a slab of thickness $L$

- heat flux prescribed on one side of the slab, consisting of a pulse of finite duration $t_{h}$

- heat exchange with the environment according to the linear Newton law on the heated side, adiabatic on the back side $(z=L)$ where temperature is measured.

\section{Parker's method}

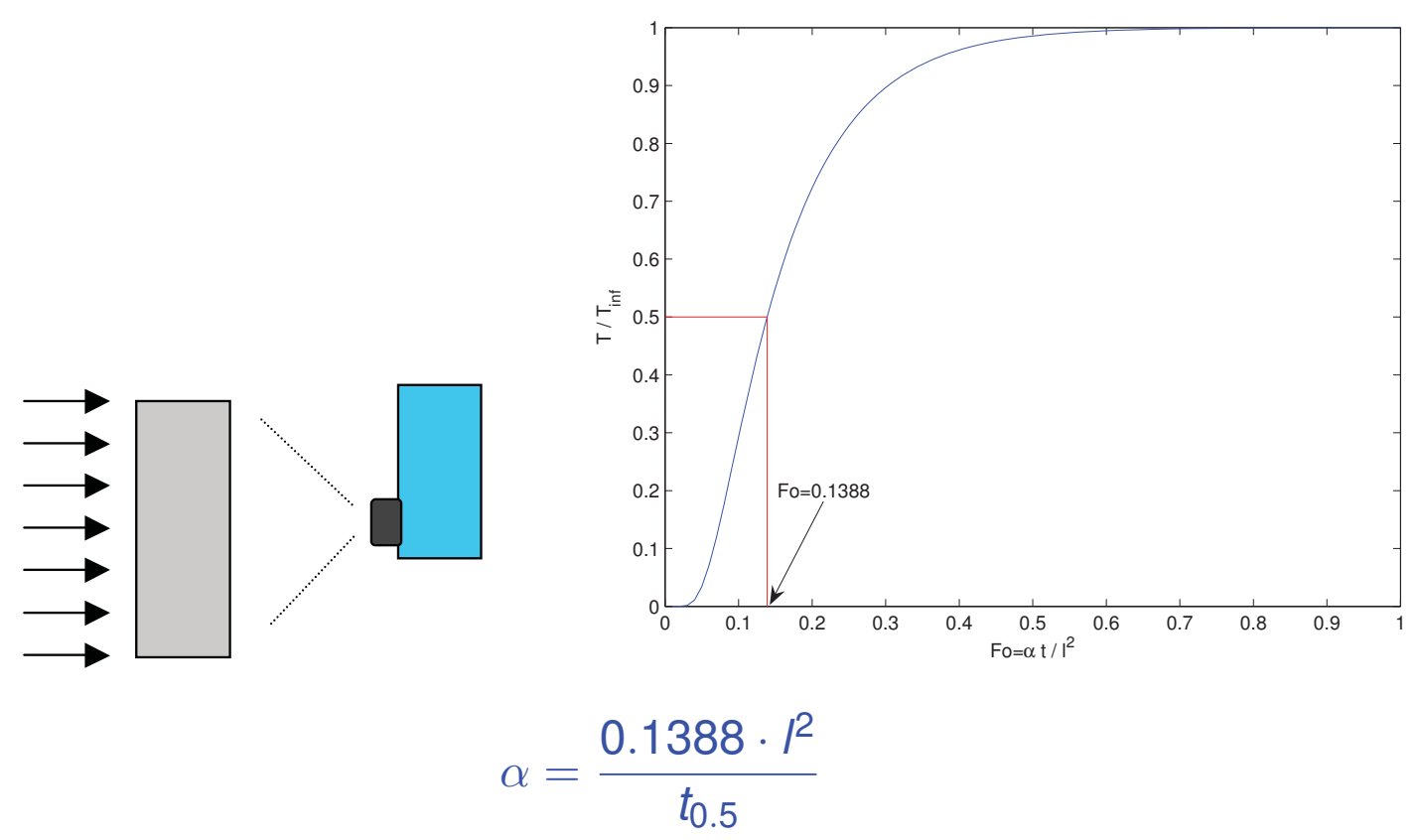

Fig. 4. Scheme of Laser Flash technique: a slab is heated on one side by a short pulse while the temperature rise is collected by radiometer (or an IR camera) on the back side. The temperature rise is depicted on the right and the formula to obtain the thermal diffusivity is given below (Parker's formula) under adiabatic conditions.

The solution for the temperature on the back side of the slab is given by:

$T(t)=\frac{Q}{h} \sum_{i=1}^{\infty} \frac{2 \sin \mu_{i}}{\mu_{i}+\sin \mu_{i} \cos \mu_{i}}\left[\exp \left(-\mu_{i}^{2} \frac{\alpha}{L^{2}}\left(t-t_{h}\right)\right)-\exp \left(-\mu_{i}^{2} \frac{\alpha}{L^{2}} t\right)\right]$ 


\subsection{1/qirt.2016.009}

$Q$ power of the pulse during the heating time $\left[\mathrm{Wm}^{-2}\right]$

$h$ heat exchange coefficient $\left[W^{-2} K^{-1}\right]$

$\alpha$ thermal diffusivity $\left[m^{2} s^{-1}\right]$

$L$ specimen thickness $[m]$

$t$ time $[s]$

$t_{h}$ pulse duration $[s]$

$\mu_{i} \quad i_{t h}$ positive root of the trascendental equation $\mu \tan \mu=B i$

$B i=\frac{h L}{\lambda}$ dimensionless Biot number

$\lambda$ thermal conductivity $\left[W m^{-1} K^{-1}\right]$

Because of the semitransparency of $\mathrm{ZrO}_{2}$ it is common practice to deposit a thin graphite layer (few microns thickness) both on the heated side, in order to increase the absorption coefficient, and on the rear side to increase the emissivity. Nonetheless, especially at high temperature, it is expected that heat is transferred from the heated graphite layer towards the back one not only by conduction but also by radiation due to the semitransparency of the TBC. In order to take into account this phenomenon Mehling [10] proposed to modify the boundary conditions of the slab according to the following formulae:

$$
\begin{gathered}
\left.\lambda \frac{\partial T}{\partial x}\right|_{x=0}=h T(0, t)+h \eta[T(0, t)-T(I, t)] \\
\left.\lambda \frac{\partial T}{\partial x}\right|_{x=1}=-h T(I, t)-h \eta[T(0, t)-T(I, t)]
\end{gathered}
$$

$$
\begin{array}{ll}
\text { - } h=4 \sigma \epsilon T^{3} & \\
\text { - } \eta=0 & \text { opaque body } \\
\text { - } \eta=1 & \text { transparent }
\end{array}
$$

Finally, in order to take into account the possibility of transparency of TBC to the laser source (that is not completely absorbed by front graphite layer) the model is hypothesized as schematized in Fig. 5 where $I_{0}$ is the energy delivered by the laser and $a$ is the absorption coefficient of the graphite layer .
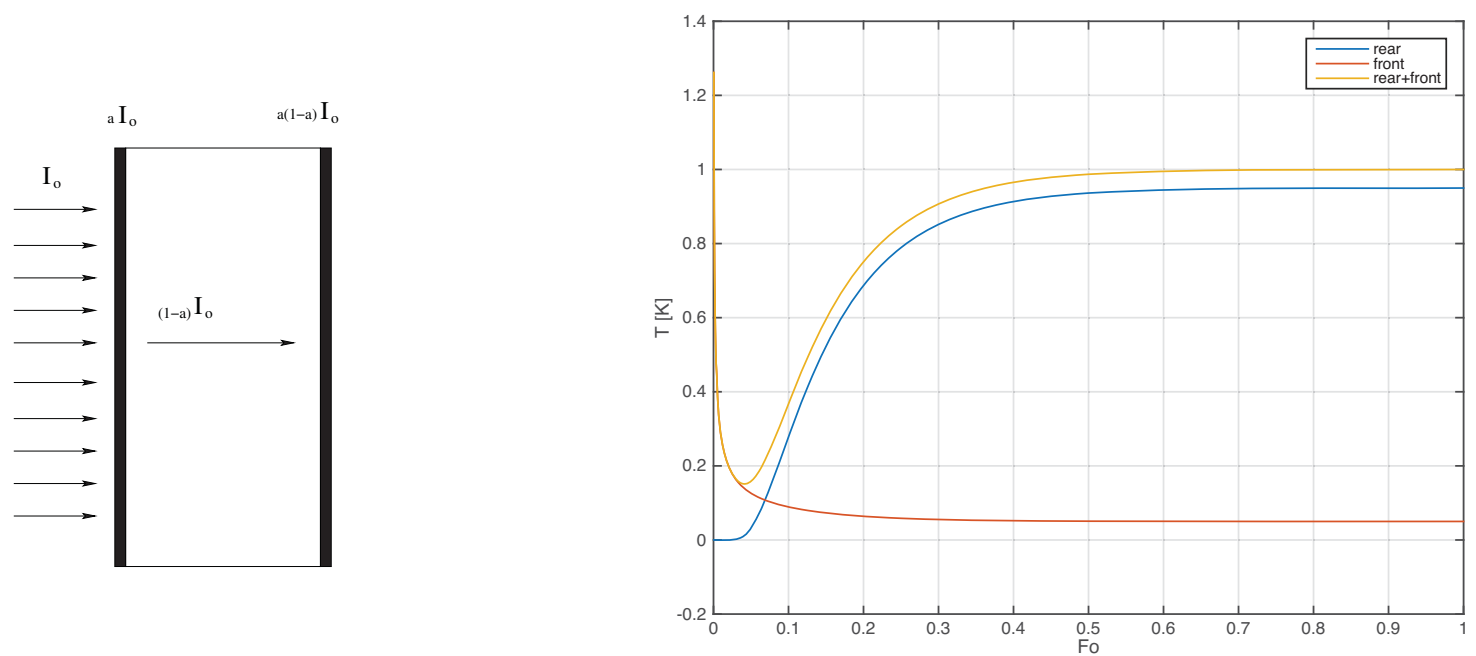

Fig. 5. Scheme of Laser Flash technique with the possible partial absorption of the laser pulse on the front graphite layer, the perfect transparency to laser radiation through the material and the absorption of the pulse on the back side. The 
solution on the back side (yellow) is due to the superposition of a front side solution (red) plus a classical rear side solution (blue).

\section{Experimental}

At room temperature IR thermography has been utilized, taken advantage of its imaging feature. Indeed by means of a mirror it is possible to capture temperature evolution both of front and rear side of the sample (see Fig. 6 for the experimental scheme and Fig. 7 for a IR image captured during a sequence).

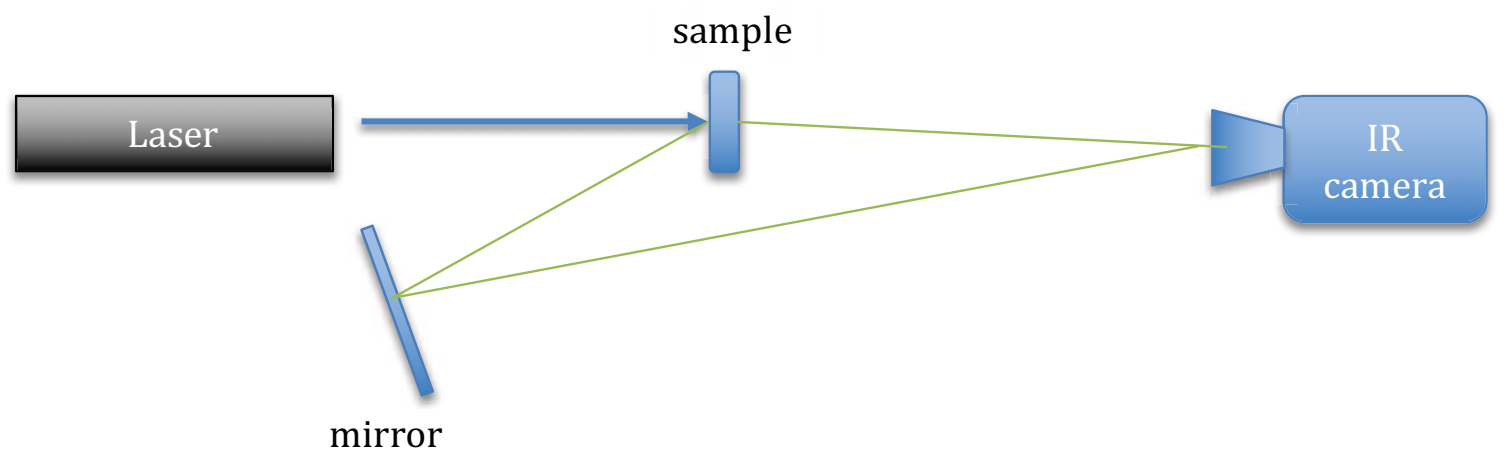

Fig. 6. Scheme of Laser Flash technique with IR camera allowing to view at the same time both front and rear side.

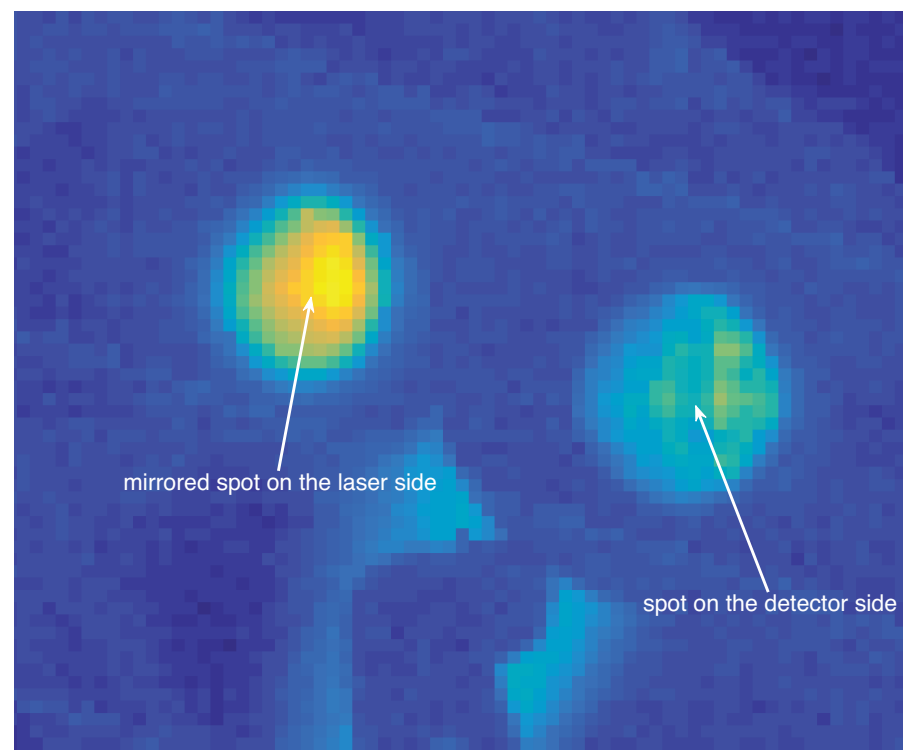

Fig. 7. IR image by thermography. It allows to view the mirrored image of the laser spot imprint after the shot on the heated sample side and, at the same time, the rising temperature of the spot on the rear surface, facing the detector.

In Fig. 8, 9 and 10, some data, fitting function and results as well are shown, proving the increasing accuracy of the models described in the previous chapter. In Fig 11 (left) the laser flash data of the same sample at increasing temperature are reported while the results are summarized in Fig. 11 (right) showing the difference in the thermal diffusivity obtained adopting the Cowan's and the proposed model. 


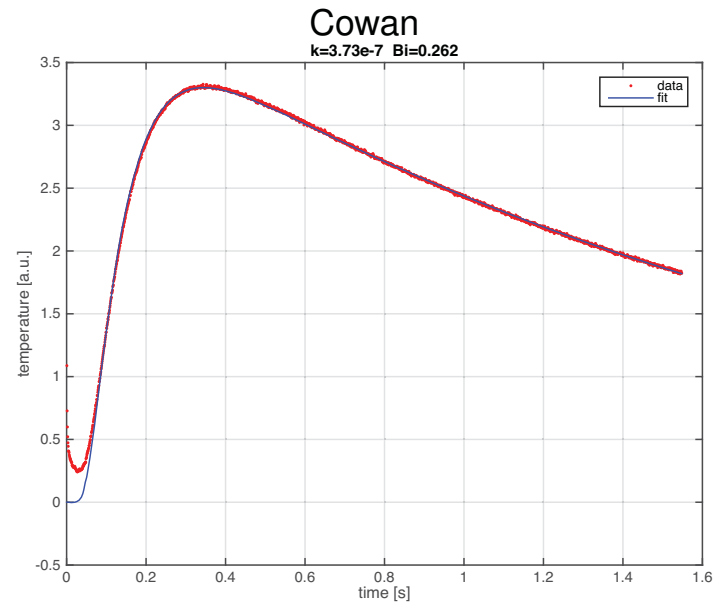

Fig. 8. Data and fitting model according to Cowan's model

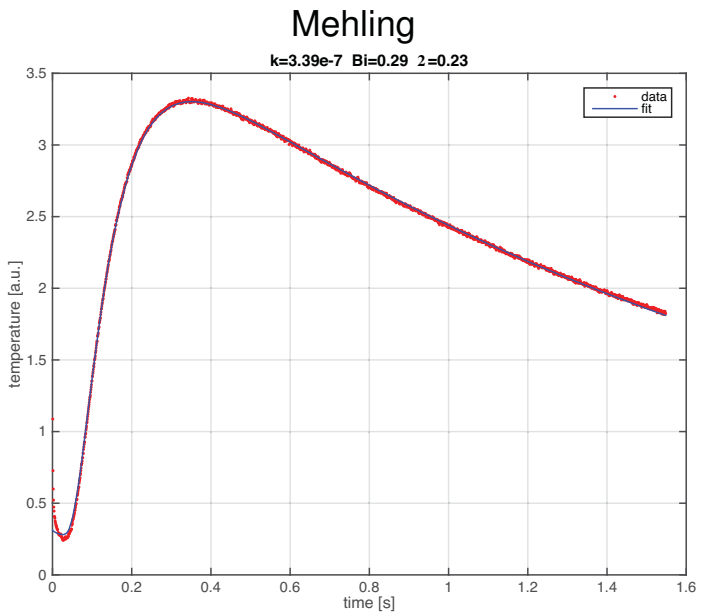

Fig. 9. Data and fitting model according to Mehling model

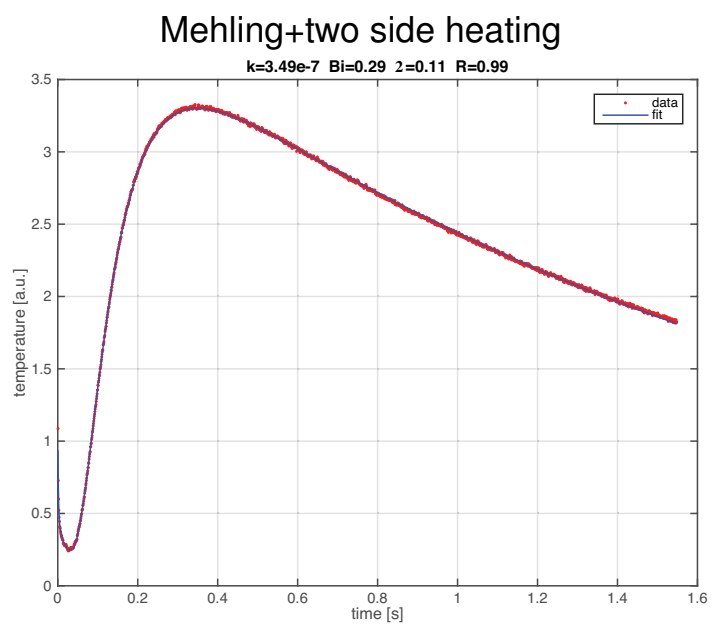

Fig. 10. Data and fitting model according to Mehling + the two side heating due to the transparency of TBC to laser light. 

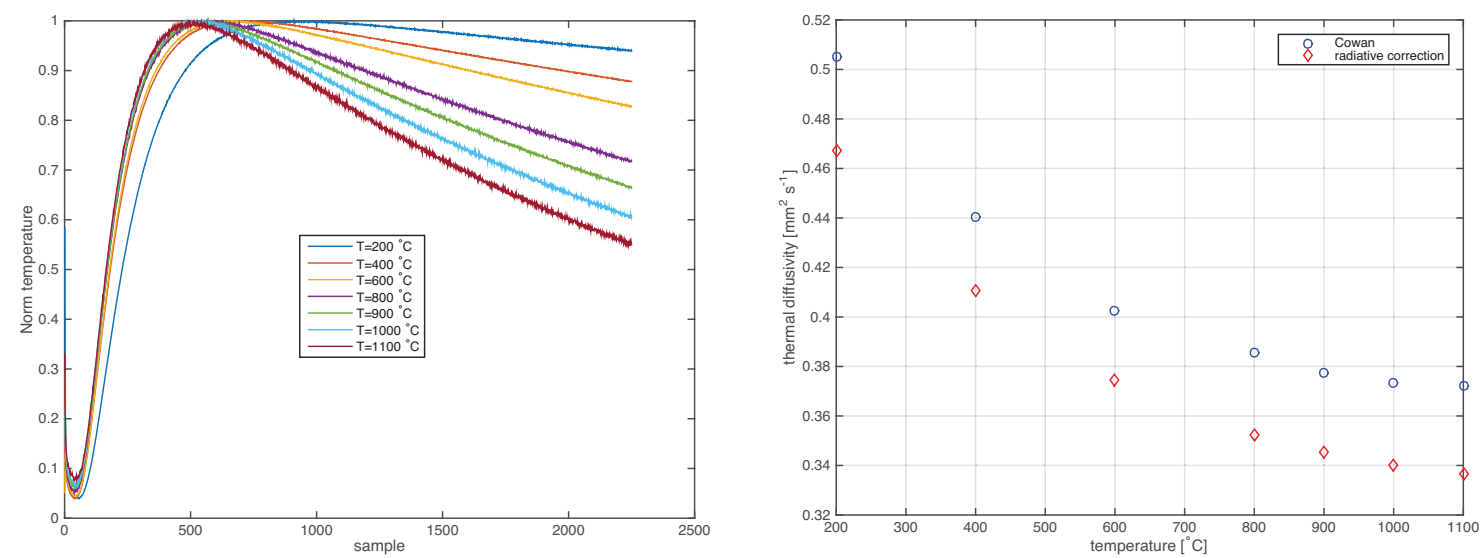

Fig. 11. On the left the temperature profile obtained on the rear side of the sample after a laser pulse. The same sample is tested at increasing temperature. On the right the results of thermal diffusivity are reported for different temperature, both according to the classical Cowan's model and to the proposed one, taking into account both the radiative exchange and the semitransparency of the sample to the laser source.

\section{Conclusion}

A new model that account for the semitransparency of $\mathrm{ZrO}_{2}$ is proposed. It allows for taking into account both the effect of radiative transfer and the semitransparency of the material to the laser source when the material is blackened by a graphite layer. Results are given for thermal diffusivity of a sample at increasing temperature showing the difference in the results adopting the classical models for Laser Flash experiments and the proposed one.

\section{References}

[1] F. M. Cernuschi, P. Bison, and A. Moscatelli. Microstructural characterization of porous thermal barrier coatings by laser flash technique. Acta Materialia, 57:3460-3471, 2009.

[2] W. Parker, R. Jenkins, C. Butler, and G. Abbott. Flash method of determining thermal diffusivity, heat capacity, and thermal conductivity. Journal of Applied Physics, 32(9):1679-1684, 1961.

[3] F. Cernuschi, S. Capelli, P. Bison, S. Marinetti, L. Lorenzoni, E. Campagnoli, C. Giolli. Non-destructive thermographic monitoring of crack evolution of thermal barrier coating coupons during cyclic oxidation aging. Acta Materialia 59 (2011) 6351-6361.

[4] F. Cernuschi, P. Bison, S. Marinetti, E. Campagnoli. Thermal diffusivity measurement by thermographic technique for the non-destructive integrity assessment of TBCs coupons. Surface \& Coatings Technology 205 (2010) 498-505.

[5] P. Bison, F. Cernuschi, S. Capelli. A thermographic technique for the simultaneous estimation of in-plane and indepth thermal diffusivities of TBCs. Surface \& Coatings Technology 205 (2011) 3128-3133.

[6] J. Manara, M. A. Schuster, H. Ratzer-Scheibe, and U. Schulze. Infrared-optical properties and heat transfer coefficients of semitransparent thermal barrier coatings. Surface \& Coatings Technology, (203):1059 - 1068, 2009.

[7] L. A. Dombrovsky, H. K. Tagne, D. Baillis and L. Gremillard. Near-infrared radiative properties of porous zirconia ceramics. Infrared Physics \& Technology 51 (2007) 44 - 53.

[8] F. Cernuschi, L. Lorenzoni, P. Bianchi, and A. Figari. The effects of sample surface treatments on laser flash thermal diffusivity measurements. Infrared Physics \& Technology, 43:133 - 138, 2002.

[9] J. A. Cape and G. W. Lehman. Temperature and finite pulse-time effects in the flash method for measuring thermal diffusivity. Journal of Applied Physics, 34(7):1909-1913, July 1963.

[10] H. Mehling, G. Hautzinger, O. Nilsson, J. Fricke, R. Hofmann, and O. Hahn. Thermal diffusivity of semitransparent materials determined by the laser-flash method applying a new analytical model. International Journal of Thermophysics, 19(3), 1998.

[11] R. D. Cowan. Pulse method of measuring thermal diffusivity at high temperatures. Journal of Applied Physics, 34(4):926-927, 1962.

[12] J. A. Cape and G. W. Lehman. Temperature and finite pulse-time effects in the flash method for measuring thermal diffusivity. Journal of Applied Physics, 34(7):1909-1913, 1963. 